\title{
Metodologias de avaliação do valor nutricional do farelo de arroz desengordurado para suínos
}

\author{
Marco Antônio Kunrath(1), Alexandre de Mello Kessler(1), Andréa Machado Leal Ribeiro(1), \\ Maitê de Moraes Vieira( ${ }^{(1)}$, Gabriel Luz da Silva(1) e Felipe D’Ávila Peixoto(1)
}

(1)Universidade Federal do Rio Grande do Sul, Departamento de Zootecnia, Avenida Bento Gonçalves, oo 7712, CEP $91540-000$ Porto Alegre, RS. E-mail: makunrath@gmail.com, akessler@ufrgs.br, aribeiro@ufrgs.br, maitevieira@yahoo.com.br, gabrielluz9@msn.com, felipedpoa@hotmail.com

Resumo - O objetivo deste trabalho foi comparar o método de substituição com o de análise de regressão, na determinação do valor nutricional do farelo de arroz desengordurado, em dietas para suínos, nas fases de crescimento e terminação. Foram conduzidos dois ensaios de digestibilidade com 16 suínos machos castrados na fase de crescimento, com peso vivo inicial de 50,0土3,1 kg, e 16 suínos machos castrados na fase de terminação, com peso vivo inicial de $95,0 \pm 3,8 \mathrm{~kg}$, alojados em gaiolas metabólicas. Utilizou-se o delineamento inteiramente casualizado com quatro tratamentos - 0, 15, 30 e 45\% de substituição da dieta-referência por farelo de arroz desengordurado - e quatro repetições, com um animal como unidade experimental. A análise de regressão foi mais precisa para estimar o valor nutricional do farelo de arroz desengordurado do que o método de substituição. Por esta análise, os coeficientes de digestibilidade aparente da matéria seca, matéria orgânica, proteína bruta e o valor de energia metabolizável do farelo de arroz desengordurado foram, respectivamente: $57,7,64,8,56,6 \%$ e $2.429 \mathrm{kcal} \mathrm{kg}^{-1}$, na fase de crescimento, e $57,7,64,7,62,6 \%$ e $2.233 \mathrm{kcal} \mathrm{kg}^{-1}$, na fase de terminação.

Termos para indexação: Oryza sativa, Sus scrofa domesticus, digestibilidade, fibra dietética, metabolizabilidade, nutrição animal.

\section{Evaluation methodologies of nutritional value of defatted rice bran for swine}

\begin{abstract}
The objective of this work was to compare the substitution method and the regression analysis method to determine the nutritional value of defatted rice bran in diets for swines at growing and finishing phases. Two digestibility bioassays were carried out with 16 barrows with initial body weight of $50.0 \pm 3.1 \mathrm{~kg}$, in the growing phase, and 16 barrows with initial body weight of $95.0 \pm 3.8 \mathrm{~kg}$, in the finishing phase, housed in metabolic cages. A completely randomized design was used with four treatments $-0,15,30$ and $45 \%$ of substitution of the reference diet by defatted rice bran - and four replications, with one animal as the experimental unit. The regression analysis was more accurate than the method of substitution to assess the nutritional value of defatted rice bran. Throught this analyse, the apparent digestibility coefficients of dry matter, organic matter, crude protein and metabolizable energy of defatted rice bran were, respectively, $57.7,64.8,56.6 \%$ and $2,429 \mathrm{kcal} \mathrm{kg}^{-1}$ on growing phase, and $57.7,64.7,62.6 \%$ and $2,233 \mathrm{kcal} \mathrm{kg}^{-1}$ on finishing phase.
\end{abstract}

Index terms: Oryza sativa, Sus scrofa domesticus, digestibility, dietary fibre, metabolizability, animal nutrition.

\section{Introdução}

A demanda crescente por cereais ricos em energia para o consumo humano e a maior disponibilidade de subprodutos ricos em fibra, procedentes de indústrias alimentícias, têm provocado aumento na utilização de matérias-primas fibrosas na alimentação animal (Noblet \& Le Goff, 2001). Além disso, a intensificação no uso de cereais e oleaginosas na produção de biocombustíveis aumenta a disponibilidade de subprodutos que podem ser uma alternativa técnica e econômica na alimentação de suínos. Entre esses, encontra-se o farelo de arroz desengordurado (FAD).

Em regiões orizícolas, os subprodutos do arroz são comumente utilizados na alimentação animal. O Rio Grande do Sul destaca-se na produção de arroz irrigado, com uma produção média anual de 7,8 milhões de toneladas (Companhia Nacional de Abastecimento, 2009). No processo de beneficiamento do arroz para o consumo humano, é obtida uma quantidade de cerca de $6,5 \%$ de FAD, que totaliza 507 mil toneladas anuais.

Pesq. agropec. bras., Brasília, v.45, n.10, p.1172-1179, out. 2010 
O FAD contém aproximadamente $15,5 \%$ de proteína, $24,3 \%$ de fibra em detergente neutro, $15,8 \%$ de fibra em detergente ácido, $1,6 \%$ de extrato etéreo e 2.530 e $2.450 \mathrm{kcal} \mathrm{kg}^{-1}$ de dieta de energia digestível e metabolizável, respectivamente. Esses valores justificam e permitem a inclusão desse subproduto na matriz nutricional de suínos (Rostagno et al., 2005).

No entanto, existem algumas limitações no uso do FAD para a alimentação de suínos. O alto teor de fibra aumenta a taxa de passagem do alimento no trato gastrintestinal e reduz a absorção dos nutrientes (Le Goff et al., 2002b). Além disso, Malathi \& Devegowda (2001) descrevem que o FAD é constituído principalmente por polissacarídeos não amiláceos (PNA). Os efeitos negativos dos PNA sobre a digestibilidade acontecem em razão do aumento da viscosidade do conteúdo intestinal, o que reduz a interação enzima/substrato pela diminuição da taxa de difusão dos nutrientes na luz intestinal e pela complexação com as enzimas digestivas (Bedford, 2000). O FAD ainda contém cerca de $80 \%$ de todo seu fósforo na forma de ácido fítico, o que torna indisponíveis, além do próprio fósforo, outros nutrientes. Essa constituição pode formar sais insolúveis com minerais e complexos com proteínas, e diminuir a atividade das enzimas proteolíticas (Selle et al., 2000).

Trabalhos publicados mostram resultados contraditórios com relação à percentagem ideal de FAD para uso como ingrediente na dieta de suínos (Warren \& Farrell, 1990; Ludke et al., 2002). Uma das questões a ser estudada é o efeito da percentagem do ingrediente-teste nos parâmetros de digestibilidade, em ensaios de metabolismo pelo método de substituição, uma vez que altas percentagens de FAD podem ter efeito negativo sobre o aproveitamento dos nutrientes. Outra fonte de variação na avaliação nutricional dos alimentos é o método utilizado em ensaios de metabolismo com suínos.

O objetivo deste trabalho foi comparar o método de substituição com o de análise de regressão na determinação do valor nutricional do FAD, em dietas para suínos em crescimento e terminação, com uso de diferentes percentagens de inclusão do ingrediente-teste.

\section{Material e Métodos}

O trabalho foi realizado no Laboratório de Ensino Zootécnico da Universidade Federal do Rio Grande do
Sul, no período de dezembro de 2008 a janeiro de 2009 . Foram conduzidos dois ensaios de digestibilidade com 16 suínos machos castrados, meios-irmãos paternos, nas fases de crescimento e de terminação, alojados em gaiolas metabólicas individuais. Os animais apresentavam peso médio inicial de $50,0 \pm 3,1$, na fase de crescimento, e de $95,0 \pm 3,8 \mathrm{~kg}$, na fase de terminação.

Utilizou-se o delineamento experimental inteiramente casualizado com quatro tratamentos quanto à percentagem da dieta-referência $(0,15,30$ e $45 \%)$, à base de milho e farelo de soja, a ser substituída por FAD (Tabela 1), de acordo com as recomendações nutricionais de Rostagno et al. (2005), para suínos em crescimento e terminação. Cada tratamento teve quatro repetições, e a unidade experimental foi composta por um animal.

Os experimentos tiveram duração de 12 dias: sete de adaptação dos animais às gaiolas e às dietas, e cinco de coleta de fezes e urina. $\mathrm{O}$ alimento foi fornecido conforme o peso metabólico $\left(\mathrm{PV}^{0,60}\right)$. A quantidade diária foi ajustada à estimativa do ganho de peso médio diário, e considerou-se um consumo de energia de 2,6 vezes a mantença, estimada em $250 \mathrm{kcal} \mathrm{EM} \times \mathrm{PV}^{0,60}$ (Noblet et al., 1993). O alimento foi distribuído em duas refeições diárias, às 8 e às $18 \mathrm{~h}$, e a água foi fornecida à vontade.

Foi utilizado o método de coleta total de fezes e urina, tendo sido o início e o final da coleta determinados pelo aparecimento de fezes marcadas com a adição de $0,5 \%$ de $\mathrm{Fe}_{2} \mathrm{O}_{3}$ às dietas. As fezes foram coletadas diariamente, pesadas, acondicionadas em sacos de plástico e conservadas em congelador a $-10^{\circ} \mathrm{C}$. Ao final do experimento foram pesadas, homogeneizadas e amostradas $(0,25 \mathrm{~kg})$, secas em estufa de ventilação forçada, a $60^{\circ} \mathrm{C}$ por 72 horas, e moídas para análises posteriores. A urina excretada foi drenada para baldes de plástico com $5 \mathrm{~mL}$ de $\mathrm{H}_{2} \mathrm{SO}_{4}$. $\mathrm{O}$ volume foi pesado diariamente e uma alíquota de $10 \%$ foi retirada e conservada sob refrigeração a $4^{\circ} \mathrm{C}$.

As análises de matéria seca (MS), matéria orgânica $(\mathrm{MO})$, fósforo $(\mathrm{P})$ e proteína bruta $(\mathrm{PB})$ das amostras de $\mathrm{FAD}$, da dieta-referência e de fezes e urina foram realizadas de acordo com a AOAC International (1999). A energia bruta (EB) foi determinada com um calorímetro de bomba isoperibólico modelo C2000, (IKA Werke GmbH \& Co. KG, Staufen, Alemanha). A fibra em detergente ácido (FDA) e a fibra em detergente neutro (FDN) foram determinadas de 
acordo com as técnicas descritas por Goering \& Van Soest (1970). Uma amostra de $100 \mathrm{~mL}$ de urina de cada animal foi seca em estufa de ventilação forçada a $65^{\circ} \mathrm{C}$, por 72 horas, e analisada quanto a seu valor de EB.

As respostas de digestibilidade e metabolizabilidade do FAD foram obtidas por dois métodos de estimativas: o método de substituição e o método de análise de regressão. No método de substituição, para as três percentagens de inclusão do $\mathrm{FAD}$, foram determinados os coeficientes de digestibilidade aparente da

Tabela 1. Ingredientes, composição calculada e analisada da dieta-referência e composição analisada do farelo de arroz desengordurado (FAD).

\begin{tabular}{|c|c|c|c|}
\hline \multirow[t]{2}{*}{ Ingredientes (\%) } & \multicolumn{2}{|c|}{ Dieta-referência } & \multirow[t]{2}{*}{ FAD } \\
\hline & Crescimento & Terminação & \\
\hline Milho & 69,39 & 76,25 & - \\
\hline Farelo de soja & 24,20 & 19,20 & - \\
\hline Gordura vegetal & 3,00 & 2,00 & - \\
\hline Calcário & 1,52 & 1,20 & - \\
\hline Fosfato bicálcico & 1,23 & 0,83 & - \\
\hline Sal & 0,44 & 0,37 & - \\
\hline Cl-Colina $(60 \%)$ & 0,07 & 0,05 & - \\
\hline L-Lisina $\mathrm{HCl}(78,8 \%)$ & 0,05 & - & - \\
\hline Premix mineral $^{(1)}$ & 0,05 & 0,05 & - \\
\hline Premix vitamínico ${ }^{(2)}$ & 0,03 & 0,03 & - \\
\hline Antioxidante & 0,02 & 0,02 & - \\
\hline Total & 100 & 100 & \\
\hline \multicolumn{4}{|l|}{ Valores Calculados $^{(3)}$} \\
\hline Matéria seca (\%) & 88,40 & 88,00 & - \\
\hline Energia metabolizável $\left(\mathrm{kcal} \mathrm{kg}^{-1}\right)$ & 3.377 & 3.363 & - \\
\hline Proteína bruta (\%) & 17,00 & 15,00 & - \\
\hline Cálcio (\%) & 0,90 & 0,70 & - \\
\hline Fósforo disponível (\%) & 0,33 & 0,25 & - \\
\hline Lisina $(\%)$ & 0,89 & 0,72 & - \\
\hline Metionina+Cistina (\%) & 0,55 & 0,51 & - \\
\hline Treonina $(\%)$ & 0,62 & 0,56 & - \\
\hline \multicolumn{4}{|l|}{ Valores Analisados $^{(3)}$} \\
\hline Matéria seca (\%) & 88,70 & 88,90 & 88,66 \\
\hline Matéria mineral (\%) & 5,05 & 4,21 & 10,47 \\
\hline Proteína bruta (\%) & 15,90 & 15,60 & 15,31 \\
\hline Extrato etéreo (\%) & 4,16 & 3,02 & 1,44 \\
\hline Fibra bruta $(\%)$ & 1,72 & 1,71 & 8,63 \\
\hline Fibra em detergente neutro (\%) & 10,60 & 13,00 & 29,30 \\
\hline Fibra em detergente ácido (\%) & 2,17 & 2,03 & 10,95 \\
\hline Energia bruta $\left(\mathrm{kcal} \mathrm{kg}^{-1}\right)$ & 3.978 & 3.993 & 3.636 \\
\hline Fósforo Total (\%) & - & - & 2,31 \\
\hline
\end{tabular}

(1)Adição por quilograma de dieta: selênio $0,30 \mathrm{mg}$; iodo $0,35 \mathrm{mg}$; cobre $8,00 \mathrm{mg}$; zinco $80,0 \mathrm{mg}$; manganês $30,0 \mathrm{mg}$. ${ }^{(2)}$ Adição por quilograma de dieta: vit. A 9600 UI; vit. D3 1800 UI; vit. E 21,6 mg; vit. K3 2,40 mg; vit. B1 1,92 mg; vit. B2 6,12 mg; vit. B6 1,86 mg; vit. B12 $0,023 \mathrm{mg}$; biotina $0,118 \mathrm{mg}$; ácido pantotênico $15,6 \mathrm{mg}$; niacina $31,2 \mathrm{mg}$; ácido fólico $0,54 \mathrm{mg} .{ }^{(3)}$ Valores com base na matéria natural.
MS, MO, PB, FDN e FDA, a metabolizabilidade aparente da EB, o valor de energia digestível (ED) e a energia metabolizável (EM) do FAD em cada fase, de acordo com as fórmulas desenvolvidas por Campbell et al. (1983), tendo-se usado como exemplo o coeficiente de digestibilidade aparente da MS: $\mathrm{CDMS}$ ingrediente $=\mathrm{MS}$ ingrediente $-\left[\left(\mathrm{MSD}_{\mathrm{DT}}\right.\right.$ - $\left.\left.(1-\mathrm{X}) \mathrm{MSD}_{\mathrm{DR}}\right) / \mathrm{X}\right]$, em que CDMS é o coeficiente de digestibilidade aparente da matéria seca; MSD é a matéria seca defecada; DT é a dieta-teste; DR é a dieta-referência; $\mathrm{X}$ é a percentagem de inclusão do ingrediente-teste na dieta-referência. No método de análise de regressão, de acordo com Adeola (2001), os coeficientes de digestibilidade e metabolizabilidade e os valores de ED e EM, obtidos nas dietas com 0, $15,30,45 \%$ de $\mathrm{FAD}$, foram submetidos à regressão linear, ocasião em que o efeito da percentagem de FAD nas dietas foi testado de forma contínua e o valor nutricional do FAD foi estimado pela extrapolação a $100 \%$ de inclusão.

As análises estatísticas foram realizadas utilizando o SAS (SAS Institute, 2002). As respostas foram submetidas à análise de variância por meio do procedimento GLM (General Linear Model), e as diferenças entre as médias foram comparadas pelo teste de Student-Newman-Keuls, a 5\% de probabilidade. As análises de regressão foram realizadas pelo procedimento REG.

\section{Resultados e Discussão}

Os valores de composição química e energia bruta do FAD (Tabela 1) foram semelhantes aos propostos por Rostagno et al. (2005), exceto para a percentagem de FDA, que foi inferior $(11,15)$, e de FDN, que foi superior $(29,45)$ ao desses autores (FDA, 15,8; FDN, 24,3). Essas variações podem estar ligadas a características do ingrediente, como origem e processamento.

A digestibilidade e metabolizabilidade aparente dos nutrientes e o valor de ED e EM das dietas foram diferentes entre as dietas estudadas, tanto no crescimento quanto na terminação (Tabela 2). Nas fases de crescimento e terminação, a inclusão de percentagens crescentes de FAD provocou efeito linear negativo $(\mathrm{p}<0,01)$ na digestibilidade, na metabolizabilidade dos nutrientes avaliados e no valor de ED e EM, exceto na digestibilidade da FDN e da FDA, que apresentou efeito quadrático $(p<0,05)$. Em ambas as fases, fica 
evidente que o aumento da inclusão de FAD reduz o aproveitamento dos nutrientes da dieta.

A inclusão de percentagens crescentes de FAD aumentou o teor de fibra das dietas experimentais. Outros autores demonstraram que as digestibilidades da MS, MO e EB (Pettersson \& Lindberg, 1997; Le Goff \& Noblet, 2001), da PB (Lindberg \& Andersson, 1998), da FDN e do FDA (Gomes et al., 2007) são afetadas negativamente com o aumento da fibra na dieta de suínos em crescimento e terminação, o que está de acordo com os resultados obtidos neste estudo.

Sessenta por cento do FAD é constituído pelos PNA, nos quais predominam os arabinoxilanos (Malathi \& Devegowda, 2001). Esses PNA aumentam a viscosidade da digesta, formam complexos com as enzimas endógenas e encapsulam os componentes nutricionais digestíveis (Bedford, 2000; Kim et al., 2005). Os arabinoxilanos também podem aumentar as perdas endógenas de $\mathrm{N}$ por promover o crescimento de microrganismos no intestino delgado, o que reduz a digestibilidade aparente da proteína (Bartelt et al., 2002).

Outro fator que pode contribuir para o baixo aproveitamento dos nutrientes é a presença do ácido fítico no FAD. No estômago e no intestino delgado, o ácido fítico possui alto potencial para complexação de moléculas carregadas positivamente, como cátions e proteínas, além de enzimas digestivas, o que diminui a digestão e aumenta as perdas endógenas (Selle et al., 2000). Assim, o ácido fítico e a complexação com os PNA são possíveis causas da redução linear, observada nas fases de crescimento e terminação, dos coeficientes

Tabela 2. Consumo de matéria seca, digestibilidade, metabolizabilidade aparente e valor de energia digestível e metabolizável de dietas com diferentes percentagens de farelo de arroz desengordurado (FAD), para suínos na fase de crescimento e terminação $^{(1)}$.

\begin{tabular}{|c|c|c|c|c|c|c|c|c|}
\hline \multirow[t]{2}{*}{ Variável } & \multicolumn{4}{|c|}{ Percentagem de inclusão de FAD } & \multirow[t]{2}{*}{$\mathrm{EPR}^{(2)}$} & \multicolumn{3}{|c|}{$\mathrm{P}$} \\
\hline & 0 & 15 & 30 & 45 & & Dieta & Linear & Quadrático \\
\hline & \multicolumn{8}{|c|}{ Fase de crescimento } \\
\hline Consumo de matéria seca $\left(\mathrm{g} \mathrm{dia}^{-1}\right)$ & 1.886 & 1.873 & 1.890 & 1.911 & 42,40 & 0,948 & - & - \\
\hline \multicolumn{9}{|l|}{ Digestibilidade aparente } \\
\hline Matéria seca (\%) & $87,5 \mathrm{a}$ & $83,8 b$ & $77,5 \mathrm{c}$ & $74,8 \mathrm{~d}$ & 0,69 & 0,001 & 0,001 & ns \\
\hline Matéria orgânica (\%) & $89,5 \mathrm{a}$ & $86,5 b$ & $81,4 \mathrm{c}$ & $78,9 \mathrm{~d}$ & 0,68 & 0,001 & 0,001 & ns \\
\hline Proteína bruta (\%) & $85,7 \mathrm{a}$ & $82,3 \mathrm{a}$ & $74,7 b$ & $74,1 b$ & 1,65 & 0,001 & 0,001 & ns \\
\hline Fibra em detergente ácido (\%) & $43,2 \mathrm{a}$ & $36,3 \mathrm{a}$ & $26,9 b$ & $38,3 \mathrm{a}$ & 2,30 & 0,003 & 0,003 & 0,007 \\
\hline Fibra em detergente neutro (\%) & $66,2 \mathrm{a}$ & $60,4 b$ & $57,0 \mathrm{~b}$ & $60,0 \mathrm{~b}$ & 1,42 & 0,006 & 0,002 & 0,010 \\
\hline Energia bruta (\%) & $88,4 \mathrm{a}$ & $86,1 \mathrm{a}$ & $81,5 b$ & $79,9 b$ & 0,75 & 0,001 & 0,001 & ns \\
\hline Fósforo total (\%) & $34,6 \mathrm{a}$ & $29,0 \mathrm{ab}$ & $18,1 \mathrm{~b}$ & $23,5 \mathrm{ab}$ & 6,49 & 0,000 & 0,001 & ns \\
\hline Metabolizabilidade aparente da energia bruta (\%) & $85,8 \mathrm{a}$ & $83,2 \mathrm{a}$ & $78,9 b$ & $77,5 b$ & 0,88 & 0,002 & 0,001 & ns \\
\hline Energia digestível $\left(\mathrm{kcal} \mathrm{kg}^{-1}\right)^{(3)}$ & $3.516 \mathrm{a}$ & $3.397 b$ & $3.197 \mathrm{c}$ & $3.084 \mathrm{~d}$ & 29,45 & 0,001 & 0,001 & ns \\
\hline \multirow[t]{2}{*}{ Energia metabolizável $\left(\mathrm{kcal} \mathrm{kg}^{-1}\right)^{(3)}$} & $3.414 \mathrm{a}$ & $3.283 b$ & $3.094 \mathrm{c}$ & $2.988 \mathrm{c}$ & 34,50 & 0,001 & 0,001 & ns \\
\hline & \multicolumn{8}{|c|}{ Fase de terminação } \\
\hline Consumo de matéria seca $\left(\mathrm{g} \mathrm{dia}^{-1}\right)$ & 2660 & 2735 & 2671 & 2630 & 86,95 & 0,868 & - & - \\
\hline \multicolumn{9}{|l|}{ Digestibilidade aparente } \\
\hline Matéria seca (\%) & $91,6 \mathrm{a}$ & $85,8 \mathrm{~b}$ & $81,9 \mathrm{c}$ & $75,9 \mathrm{~d}$ & 0,56 & 0,001 & 0,001 & ns \\
\hline Matéria orgânica (\%) & $93,0 \mathrm{a}$ & $88,3 b$ & $85,1 \mathrm{c}$ & $79,8 \mathrm{~d}$ & 0,51 & 0,001 & 0,001 & ns \\
\hline Proteína bruta (\%) & $91,1 \mathrm{a}$ & $84,6 \mathrm{a}$ & $81,9 b$ & $78,6 \mathrm{~b}$ & 0,64 & 0,001 & 0,001 & ns \\
\hline Fibra em detergente ácido (\%) & $71,2 \mathrm{a}$ & $44,7 \mathrm{a}$ & $41,3 b$ & $38,1 \mathrm{~b}$ & 3,20 & 0,001 & 0,001 & 0,004 \\
\hline Fibra em detergente neutro $(\%)$ & $83,7 \mathrm{a}$ & $66,3 b$ & $64,0 \mathrm{~b}$ & $59,5 b$ & 1,81 & 0,001 & 0,001 & 0,007 \\
\hline Energia bruta (\%) & $91,7 \mathrm{a}$ & $87,8 \mathrm{a}$ & $85,2 b$ & $80,4 b$ & 0,50 & 0,001 & 0,001 & ns \\
\hline Fósforo total (\%) & $44,4 \mathrm{a}$ & $32,5 \mathrm{ab}$ & $21,3 b$ & $16,6 b$ & 8,59 & 0,003 & 0,001 & ns \\
\hline Metabolizabilidade aparente da energia bruta (\%) & $88,8 \mathrm{a}$ & $85,1 \mathrm{a}$ & $82,0 \mathrm{~b}$ & $77,0 \mathrm{~b}$ & 0,41 & 0,001 & 0,001 & ns \\
\hline Energia digestível $\left(\mathrm{kcal} \mathrm{kg}^{-1}\right)^{(3)}$ & $3.662 \mathrm{a}$ & $3.480 \mathrm{~b}$ & $3.336 \mathrm{c}$ & $3.046 \mathrm{~d}$ & 19,70 & 0,001 & 0,003 & ns \\
\hline Energia metabolizável $\left(\mathrm{kcal} \mathrm{kg}^{-1}\right)^{(3)}$ & $3.545 \mathrm{a}$ & $3.373 b$ & $3.211 \mathrm{c}$ & $2.920 \mathrm{c}$ & 16,51 & 0,001 & 0,001 & ns \\
\hline
\end{tabular}

${ }^{(1)}$ Médias seguidas por letras iguais não diferem entre si pelo teste SNK, a 5\% de probabilidade. (2)Erro-padrão residual. ${ }^{(3)}$ Expressos na matéria natural.

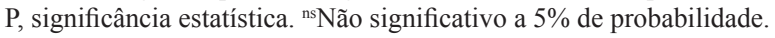


de digestibilidade aparente da PB, com o aumento da inclusão de FAD na dieta.

$\mathrm{Na}$ fase de crescimento, a percentagem de inclusão de farelo de arroz influenciou a estimativa de digestibilidade aparente da MS, MO, FDA e FDN (Tabela 3). As dietas com 15\% de FAD apresentaram as maiores estimativas de digestibilidade, não tendo havido diferença entre as inclusões de 30 e $45 \%$. $\mathrm{Na}$ fase de terminação, a percentagem de inclusão de FAD não influenciou as respostas avaliadas, exceto quanto à digestibilidade da FDA, que foi superior nas inclusões 15 e $30 \%$.

O melhor aproveitamento do FAD, observado com $15 \%$ de inclusão na fase de crescimento, pode estar associado ao menor efeito sobre a cinética digestiva dos suínos. Uma grande parte da capacidade digestiva do suíno está relacionada ao tempo de retenção da dieta no trato gastrintestinal. Embora os valores do tempo de retenção médio (TRM) na literatura sejam muito variáveis, Le Goff et al. (2002b) relataram que suínos em crescimento e terminação possuem um TRM de 33 e 37 horas, respectivamente. $\mathrm{O}$ incremento da fibra dietética aumenta a taxa de passagem da digesta (Partanen et al., 2007). O aumento da taxa de passagem pode ser um fator que explica parcialmente a influência do teor de FAD no aproveitamento dos próprios nutrientes que o constituem, em associação à menor acessibilidade ou menor efeito das enzimas sobre os componentes do FAD. Este efeito, no entanto, tornouse menos pronunciado com o aumento do peso vivo dos animais. Esses resultados estão de acordo com Noblet \& Shi (1994), Le Goff \& Noblet (2001) e Le Goff et al. (2002b), que observaram melhor aproveitamento da dieta em porcas adultas e em suínos em terminação, quando comparados a animais em crescimento, embora Le Goff et al. (2002a) não tenham constatado melhora na utilização da energia em dietas com elevado teor de fibra para suínos na fase de terminação.

O método usado para estimar o valor nutricional dos ingredientes na alimentação animal pode influenciar os resultados. Em ensaios de metabolismo, a dieta-referência é em parte substituída pelo

Tabela 3. Digestibilidade e metabolizabilidade aparente e valor de energia digestível e metabolizável do farelo de arroz desengordurado (FAD) para suínos na fase de crescimento e terminação, com uso do método de substituição ${ }^{(1)}$.

\begin{tabular}{|c|c|c|c|c|c|}
\hline \multirow[t]{2}{*}{ Variáveis } & \multicolumn{3}{|c|}{ Percentagem de inclusão de FAD } & \multirow[t]{2}{*}{$\mathrm{P}$} & \multirow[t]{2}{*}{$\mathrm{EPR}^{(2)}$} \\
\hline & 15 & 30 & 45 & & \\
\hline & \multicolumn{4}{|c|}{ Fase de crescimento } & \\
\hline \multicolumn{6}{|l|}{ Digestibilidade aparente } \\
\hline Matéria seca (\%) & $66,2 \mathrm{a}$ & $55,5 b$ & $59,9 \mathrm{ab}$ & 0,015 & 1,98 \\
\hline Matéria orgânica (\%) & $74,9 \mathrm{a}$ & $67,7 b$ & $69,8 \mathrm{ab}$ & 0,041 & 1,79 \\
\hline Proteína bruta (\%) & 66,2 & 55,8 & 61,5 & 0,442 & 5,04 \\
\hline Fibra em detergente ácido (\%) & $73,3 \mathrm{a}$ & $60,1 b$ & $55,5 b$ & 0,001 & 1,36 \\
\hline Fibra em detergente neutro $(\%)$ & $74,6 \mathrm{a}$ & $63,3 b$ & $63,9 b$ & 0,001 & 1,42 \\
\hline Energia bruta $(\%)$ & 74,7 & 64,9 & 69,0 & 0,078 & 2,61 \\
\hline Fósforo total (\%) & 21,2 & 8,7 & 20,2 & 0,060 & 6,66 \\
\hline Metabolizabilidade aparente da energia bruta (\%) & 70,3 & 62,2 & 66,7 & 0,520 & 4,78 \\
\hline Energia digestível $\left(\mathrm{kcal} \mathrm{kg}^{-1}\right)^{(3)}$ & 2.716 & 2.359 & 2.507 & 0,078 & 107,00 \\
\hline Energia metabolizável $\left(\mathrm{kcal} \mathrm{kg}^{-1}\right)^{(3)}$ & 2.555 & 2.263 & 2.424 & 0,520 & 195,90 \\
\hline \multicolumn{6}{|c|}{ Fase de terminação } \\
\hline \multicolumn{6}{|l|}{ Digestibilidade aparente } \\
\hline Matéria seca (\%) & 53,5 & 59,5 & 56,7 & 0,365 & 2,83 \\
\hline Matéria orgânica (\%) & 63,9 & 69,5 & 67,2 & 0,294 & 2,34 \\
\hline Proteína bruta (\%) & 53,9 & 63,9 & 63,6 & 0,066 & 2,83 \\
\hline Fibra em detergente ácido (\%) & $71,6 \mathrm{a}$ & $66,6 \mathrm{a}$ & $56,5 b$ & 0,004 & 2,02 \\
\hline Fibra em detergente neutro $(\%)$ & 62,1 & 63,8 & 59,6 & 0,550 & 2,37 \\
\hline Energia bruta (\%) & 63,2 & 68,2 & 65,8 & 0,522 & 2,97 \\
\hline Fósforo total (\%) & 18,6 & 10,3 & 9,7 & 0,330 & 8,53 \\
\hline Metabolizabilidade aparente da energia bruta (\%) & 61,8 & 64,3 & 62,0 & 0,826 & 3,02 \\
\hline Energia digestível $\left(\mathrm{kcal} \mathrm{kg}^{-1}\right)$ & 2.310 & 2.493 & 2.406 & 0,522 & 121,90 \\
\hline Energia metabolizável $\left(\mathrm{kcal} \mathrm{kg}^{-1}\right)$ & 2.260 & 2.350 & 2.268 & 0,826 & 123,50 \\
\hline
\end{tabular}

Pesq. agropec. bras., Brasília, v.45, n.10, p.1172-1179, out. 2010 
ingrediente-teste e, pela diferença, estima-se o coeficiente de digestibilidade e metabolizabilidade, assim como o valor de ED e EM. Quando a proporção do ingrediente-teste incluída constitui uma pequena fração da dieta, a multiplicação do erro pode ser substancial (Campbell et al., 1983). Neste trabalho, a metabolizabilidade da EB apresentou erros-padrão de $7,19,2,30$ e $2,39 \%$, na fase de crescimento, para as percentagens 15,30 , e $45 \%$ de substituição, respectivamente. $\mathrm{O}$ erro-padrão associado com o valor de ED diminuiu à medida que o FAD foi incorporado na dieta, o que indica baixa confiabilidade na estimativa média aos $15 \%$ de substituição. Por essa razão, tem sido sugerido que apenas um nível de inclusão não é recomendado para estimar o valor nutricional de ingredientes para monogástricos. Dessa maneira, vários níveis de inclusão do ingrediente-teste e análise de regressão são os mais indicados para a obtenção de resultados mais precisos (Sibbald \& Slinger, 1963).

$\mathrm{Na}$ extrapolação para os $100 \%$ de inclusão de FAD, por meio da equação linear $\mathrm{Y}=85,8-0,199 \times \% \mathrm{FAD}$, a estimativa do coeficiente de metabolizabilidade da EB foi de $65,9 \pm 1,73 \%$, na fase de crescimento. $\mathrm{O}$ erro-padrão associado a esse valor foi menor que os determinados pelo método de substituição, em qualquer percentagem de inclusão do $\mathrm{FAD}$, o que indica maior precisão desse método na estimativa do valor nutricional de ingredientes. Resultados semelhantes foram encontrados por Rodríguez et al. (2005) que, ao estimar o valor de EM da semente de linhaça para frangos de corte por regressão, obtiveram menor erro-padrão em comparação ao método de substituição. Uma limitação desse método é que, se o modelo não for linear e sim quadrático ou cúbico, não é possível estimar o valor nutricional dos alimentos por extrapolação. Assim, para as variáveis que apresentaram resposta quadrática (Tabela 2), não foi possível estimar o valor de energia digestível e metabolizável do FAD (Tabela 4).

Os valores dos coeficientes de digestibilidade e metabolizabilidade aparente, assim como o conteúdo de ED e EM do FAD, determinados pelo método de substituição, foram similares aos calculados pela regressão. O coeficiente de digestibilidade aparente da MS do FAD, de $57,7 \%$ na fase de crescimento e terminação, estimado por regressão (Tabela 4), foi semelhante ao resultado encontrado por Lima et al. (2000). Com relação à PB, foi verificado um coeficiente de digestibilidade aparente de 56,6\%, no crescimento e de $62,6 \%$ na terminação. Por sua vez, Fialho et al. (1995), Fundación Española para el Desarrollo de

Tabela 4. Equação de regressão linear para estimativa da digestibilidade e metabolizabilidade aparente e do valor de energia digestível e metabolizável do farelo de arroz desengordurado (FAD), para suínos na fase de crescimento e terminação.

\begin{tabular}{|c|c|c|c|c|}
\hline Variáveis & Equação da regressão & Valor estimado $^{(1)}$ & $\mathrm{EPR}^{(2)}$ & $\mathrm{R}^{2}$ \\
\hline & \multicolumn{4}{|c|}{ Fase de crescimento } \\
\hline \multicolumn{5}{|l|}{ Digestibilidade aparente de: } \\
\hline Matéria seca (\%) & $\mathrm{y}=87,6-0,299 \mathrm{FAD}$ & 57,7 & 1,51 & 92,3 \\
\hline Matéria orgânica (\%) & $\mathrm{y}=89,6-0,248 \mathrm{FAD}$ & 64,8 & 1,38 & 90,8 \\
\hline Proteína bruta (\%) & $\mathrm{y}=85,6-0,291 \mathrm{FAD}$ & 56,6 & 3,40 & 69,0 \\
\hline Energia bruta $(\%)$ & $\mathrm{y}=88,5-0,202 \mathrm{FAD}$ & 68,3 & 1,52 & 84,2 \\
\hline Fósforo Total (\%) & $y=33,6-0,264$ FAD & 7,2 & 7,12 & 37,6 \\
\hline Metabolizabilidade aparente da energia bruta (\%) & $\mathrm{y}=85,8-0,199 \mathrm{FAD}$ & 65,9 & 1,73 & 80,2 \\
\hline Energia digestível $\left(\mathrm{kcal} \mathrm{kg}^{-1}\right)^{(3)}$ & $\mathrm{y}=3.523-10,1 \mathrm{FAD}$ & 2.519 & 58,00 & 90,1 \\
\hline$\underline{\text { Energia metabolizável }\left(\mathrm{kcal} \mathrm{kg}^{-1}\right)^{(3)}}$ & $\mathrm{y}=3.416-9,9$ FAD & 2.429 & 66,10 & 87,2 \\
\hline \multicolumn{5}{|c|}{ Fase de terminação } \\
\hline \multicolumn{5}{|l|}{ Digestibilidade aparente de: } \\
\hline Matéria seca (\%) & $\mathrm{y}=91,5-0,339 \mathrm{FAD}$ & 57,7 & 1,15 & 96,5 \\
\hline Matéria orgânica (\%) & $\mathrm{y}=92,9-0,283 \mathrm{FAD}$ & 64,7 & 1,03 & 95,8 \\
\hline Proteína bruta $(\%)$ & $\mathrm{y}=90,2-0,276 \mathrm{FAD}$ & 62,6 & 1,56 & 90,6 \\
\hline Energia bruta $(\%)$ & $\mathrm{y}=91,7-0,242 \mathrm{FAD}$ & 67,5 & 1,04 & 94,5 \\
\hline Fósforo Total (\%) & $\mathrm{y}=43,2-0,650 \mathrm{FAD}$ & $-21,8$ & 8,20 & 66,2 \\
\hline Metabolizabilidade aparente da energia bruta (\%) & $\mathrm{y}=88,9-0,252 \mathrm{FAD}$ & 63,7 & 0,88 & 96,3 \\
\hline Energia digestível $\left(\mathrm{kcal} \mathrm{kg}^{-1}\right)^{(3)}$ & $\mathrm{y}=3.676-13,0 \mathrm{FAD}$ & 2.376 & 50,40 & 95,4 \\
\hline Energia metabolizável $\left(\mathrm{kcal} \mathrm{kg}^{-1}\right)^{(3)}$ & $\mathrm{y}=3.563-13.3 \mathrm{FAD}$ & 2.233 & 46,30 & 96,2 \\
\hline
\end{tabular}

${ }^{(1)}$ Estimativa da digestibilidade e do valor de energia digestível do FAD por extrapolação a $100 \%$. ${ }^{(2)}$ Erro-padrão residual. ${ }^{(3)}$ Valores expressos na matéria natural. 
la Nutrición Animal (2003) e Rostagno et al. (2005) encontraram coeficiente de digestibilidade aparente da PB do FAD de 68, 68 e 74\%, respectivamente. A baixa digestibilidade da PB pode estar associada ao elevado teor de fósforo total do $\operatorname{FAD}(2,31 \%)$, que foi superior ao dos estudos citados anteriormente $(2,1,1,77$ e 1,81\% respectivamente). O nível de $\mathrm{P}$ total está correlacionado ao teor de ácido fítico, e esse componente possui alto grau de complexação com proteínas no estômago e no intestino delgado, o que diminui o aproveitamento da PB (Selle et al., 2000). Essa afirmação é confirmada pelos baixos valores de digestibilidade medidos para o $\mathrm{P}$ das dietas com FAD. Houve redução linear no coeficiente de digestibilidade aparente do $\mathrm{P}$ total da dieta, o que leva a estimativas muito baixas desse parâmetro no FAD: crescimento $7,2 \%$ e terminação $-21,8 \%$. Essas equações foram as de mais baixo coeficiente de determinação, e não apresentaram vantagem evidente no EPR. Uma explicação possível para esse comportamento, além da baixa digestibilidade do $\mathrm{P}$ fítico presente em alta quantidade no FAD, é a excreção fecal de $\mathrm{P}$, que resulta em valores reduzidos de digestibilidade aparente deste mineral, o que resultou numa equação de regressão cujo coeficiente linear foi muito alto, e levou a valores irreais na extrapolação para $100 \%$ de FAD. Dessa forma, as estimativas pelo método de substituição (Tabela 4) parecem ser mais realistas, com os coeficientes médios de digestibilidade aparente do P do FAD estimados em $16,7 \%$ no crescimento e $12,9 \%$ na terminação. Esses valores estão abaixo dos $25 \%$ de biodisponibilidade, estimada por resistência e mineralização óssea, medidos por Cromwell (1992).

$\mathrm{O}$ valor de EM do FAD foi de $2.429 \mathrm{kcal} \mathrm{kg}^{-1}$ no crescimento e $2.233 \mathrm{kcal} \mathrm{kg}^{-1}$ na terminação (Tabela 4). A estimativa mais baixa de EM do FAD na terminação contrasta com a citada maior capacidade de digestão da fibra em suínos de maior peso vivo. Uma explicação possível para esse resultado, além da evidência de que não houve melhor aproveitamento do FAD pelos suínos em terminação, é que a extrapolação para $100 \%$ foi afetada por colinearidade associada à melhor digestibilidade da EB com $0 \%$ de FAD na terminação, quando comparada à fase de crescimento, o que levou à obtenção de equação linear com maior valor de intercepto em Y $\left(3.563 \times 3.416 \mathrm{kcal} \mathrm{kg}^{-1}\right)$ e também com maior inclinação (13,3 x 9,9 kcal/\%FAD). Fialho et al. (1995) relataram valor médio de EM para o FAD de $2.384 \mathrm{kcal} \mathrm{kg}^{-1}$ e não verificaram diferenças nas medidas realizadas com suínos de peso médio de 29,3 ou $69,7 \mathrm{~kg}$ de PV. Rostagno et al. (2005) relataram, quanto ao $\mathrm{FAD}$, uma EM de $2.450 \mathrm{kcal} \mathrm{kg}^{-1}$, valor próximo da estimativa na fase de crescimento do presente trabalho, enquanto valores mais baixos, de 2.199 e $2.110 \mathrm{kcal} \mathrm{kg}^{-1}$ de FAD, foram citados por Lima et al. (2000) e por Fundación Española para el Desarrollo de la Nutrición Animal (2003), respectivamente.

Lima et al. (2000) utilizaram suínos com peso médio de $58,8 \mathrm{~kg}$, enquanto as compilações de Fundación Española para el Desarrollo de la Nutrición Animal (2003) e Rostagno et al. (2005) não informam as características dos animais utilizados nos ensaios. Diferenças nas estimativas da EM podem estar associadas a características do alimento, como composição química e processamento, do animal, como peso vivo, sexo e genótipo, e aos procedimentos experimentais utilizados, como variações na percentagem de substituição do ingrediente-teste (Le Goff et al., 2002a).

\section{Conclusão}

O método de análise de regressão é mais preciso em estimar a digestibilidade dos nutrientes e o valor energético do farelo de arroz desengordurado, do que o método de substituição, com exceção de variáveis que apresentam comportamento quadrático e não foram estimadas pelo primeiro método.

\section{Agradecimentos}

Ao Conselho Nacional de Desenvolvimento Científico e Tecnológico, pela bolsa concedida ao primeiro autor.

\section{Referências}

ADEOLA, O. Digestion and balance techniques in pigs. IN: LEWIS, A.J.; SOUTHERN, L.L. (Ed.). Swine nutrition. 2.ed. Boca Raton: CRC, 2001. p.903-916.

AOAC INTERNATIONAL. Official methods of analysis of the Association of Official Analytical Chemists. $16^{\text {th }}$ ed. Washington: AOAC International, 1999. 1141p.

BARTELT, J.; JADAMUS, A.; WIESE, F.; SWIECH, E.; BURACZEWSKA, L.; SIMON, O. Apparent precaecal digestibility of nutrients and level of endogenous nitrogen in digesta of the small intestine of growing pigs as affected by various digesta viscosities. Archives of Animal Nutrition, v.56, p.93-107, 2002. 
BEDFORD, M.R. Exogenous enzymes in monogastric nutrition: their current value and future benefits. Animal Feed Science and Technology, v.86, p.1-13, 2000.

CAMPBELL, G.L.; CAMPBELL, L.D.; BLAIR, R. Calculation of metabolizable energy for ingredients incoporated at low levels into a reference diet. Poultry Science, v.62, p.705-707, 1983.

COMPANHIA NACIONAL DE ABASTECIMENTO. Acompanhamento da safra brasileira de grãos 2008/09: décimo primeiro levantamento. Brasília: CONAB, 2009. 39p.

CROMWELL, G.L. Biological availability of phosphorus in feedstuffs for pigs. Pig News and Information, v.13, p.75-78, 1992.

FIALHO, E.T.; BARBOSA, H.P.; ALBINO, L.F.T. Chemical composition, digestible protein and energy values of some alternative feedstuffs for pigs in Brazil. Animal Feed Science and Technology, v.55, p.239-245, 1995.

FUNDACIÓN ESPAÑOLA PARA EL DESARROLLO DE LA NUTRICIÓN ANIMAL. Tablas FEDNA de composición y valor nutritivo de alimentos para la fabricación de piensos compuestos. 2.ed. Madrid: 2003. 253p. Online. Disponible en: <http://www.etsia. upm.es/fedna/tablas.htm>. Leído el: 02 out. 2009.

GOERING, H.K.; VAN SOEST, P.J. Forage fiber analysis (apparatus, reagents, procedures and some aplications). Washington: Agricultural Research Service, 1970. 79p.

GOMES, J.D.F.; PUTRINO, S.M.; GROSSKLAUS, C.; UTIYAMA, C.E.; OETTING, L.L.; SOUZA, L.W. de O.; FUKUSHIMA, R.S.; FAGUNDES, A.C.A.; SOBRAL, P.J. do A.; LIMA, C.G. de. Efeitos do incremento de fibra dietética sobre a digestibilidade, desempenho e características de carcaça: suínos em crescimento e terminação. Semina: Ciências Agrárias, v.28, p.483-492, 2007.

KIM, J.C.; SIMMINS, P.H.; MULLAN, B.P.; PLUSKE, J.R. The digestible energy value of wheat for pigs, with special reference to the post-weaned animal. Animal Feed Science and Technology, v.122, p.257-287, 2005.

LE GOFF, G.; DUBOIS S.; VAN MILGEN, J.; NOBLET, J. Influence of dietary fibre level on digestive and metabolic utilization of energy in growing and finishing pigs. Animal Research, v.51, p.245-259, 2002a.

LE GOFF, G.; NOBLET, J. Comparative total tract digestibility of dietary energy and nutrients in growing pigs and adult sows. Journal of Animal Science, v.79, p.2418-2427, 2001.

LE GOFF, G.; VAN MILGEN, J.; NOBLET, J. Influence of dietary fibre on digestive utilization and rate of passage in growing pigs, finishing pigs and adult sows. Animal Science, v.74, p.503-515, 2002b.

LIMA, G.J.M.M. de; MARTINS, R.R.; ZANOTTO, D.L.; BRUM, P.A.R. de. Composição química e valores de energia de subprodutos do beneficiamento de arroz. Concórdia: Embrapa Suínos e Aves, 2000. 2p. (Embrapa Suínos e Aves. Comunicado técnico, 244).
LINDBERG, J.E.; ANDERSSON, C. The nutritive value of barley-based diets with forage meal inclusion for growing pigs based on total tract digestibility and nitrogen utilization. Livestock Production Science, v.56, p.43-52, 1998.

LUDKE, M. do C.M.M.; LÓPES, J.; LUDKE, J.V.; NICOLAIEWSKY, S. Utilização da fitase em dietas com ou sem farelo de arroz desengordurado para suínos em crescimento/terminação. Revista Brasileira de Zootecnia, v.31, p.2002-2010, 2002.

MALATHI, V.; DEVEGOWDA, G. In vitro evaluation of nonstarch polysaccharide digestibility of feed ingredients by enzymes. Poultry Science, v.80, p.302-305, 2001.

NOBLET, J.; LE GOFF, G. Effect of dietary fiber on the energy value of feeds for pigs. Animal Feed Science and Technology, v.90, p.35-52, 2001.

NOBLET, J.; SHI, X.S. Effect of body weight on digestive utilization of energy and nutrients of ingredients and diets in pigs. Livestock Production Science, v.37, p.323-338, 1994.

NOBLET, J.; SHI, X.S.; DUBOIS, S. Metabolic utilization of dietary energy and nutrients for maintenance energy requirements in sows: basis for a net energy system. British Journal of Nutrition, v.70, p.407-419, 1993.

PARTANEN, K.; JALAVA, T.; VALAJA, J. Effects of a dietary organic acid mixture and of dietary fibre levels on ileal and faecal nutrient apparent digestibility, bacterial nitrogen flow, microbial metabolite concentrations and rate of passage in the digestive tract of pigs. Animal, v.1, p.389-401, 2007.

PETTERSSON, A.; LINDBERG, J.E. Ileal and total tract digestibility in pigs of naked and hulled barley with different starch composition. Animal Feed Science and Technology, v.66, p.97-109, 1997.

RODRÍGUEZ, M.L.; ORTIZ, L.T.; ALZUETA, C.; REBOLÉ, A.; TREVIÑO, J. Nutritive value of high-oleic acid sunflower seed for broiler chickens. Poultry Science, v.84, p.395-402, 2005.

ROSTAGNO, H.S.; ALBINO, L.F.T.; DONZELE, J.L.; GOMES, P.C.; OLIVEIRA, R.F.; LOPES, D.C.; FERREIRA, A.S.; BARRETO, S.L.T. Tabelas brasileiras para aves e suínos: composição de alimentos e exigências nutricionais. 2.ed. Viçosa: UFV, 2005. 186p.

SAS INSTITUTE. SAS/STAT: guide for personal computers. Cary: SAS Institute, 2002.

SELLE, P.H.; RAVINDRAN, V.; CALDWELL, A.; BRYDEN, W.L. Phytate and phytase: consequences for protein utilisation. Nutrition Research Reviews, v.13, p.255-278, 2000.

SIBBALD, I.R.; SLINGER, S.J. A biological assay for metabolizable energy in poultry feed ingredients together with findings which demonstrate some of problems associated with evaluation of fats. Poultry Science, v.42, p.313-325, 1963.

WARREN, B.E.; FARRELL, D.J. The nutritive value of full-fat and defatted Australian rice bran. II. Growth studies with chickens, rats and pigs. Animal Feed Science and Technology, v.27, p.229-246, 1990.

Recebido em 7 de abril de 2010 e aprovado em 30 de setembro de 2010 